\title{
MODERATED MEDIATION OF STRESS
}

Brough, P., Drummond, S., \& Biggs, A. (in press). Job support, coping and control: Assessment of simultaneous impacts within the occupational stress process. Journal of Occupational Health Psychology,

Job support, coping, and control: Assessment of simultaneous impacts within the occupational stress process

Paula Brough,* Suzie Drummond, and Amanda Biggs, School of Applied Psychology, Griffith University, Australia

*Correspondence concerning this article should be addressed to: Paula Brough, School of Applied Psychology, Griffith University, Mount Gravatt Campus, Queensland 4122, Australia. Email: p.brough@griffith.edu.au; Telephone: +61 737353378. 


\title{
MODERATED MEDIATION OF STRESS
}

\begin{abstract}
The assessment of occupational stress is marred by an overwhelming adoption of simplistic research designs that generally fail to represent the complex reality of the occupational stress process. Informed by the theoretical tenants of both the transactional stress model and the job demands control-support (JDC-S) model, this paper presents a rare simultaneous assessment of how two types of job demands (cognitive and emotional) are both moderated by job control and social support and mediated by coping for the prediction of work engagement and psychological strain over time. Self-report surveys were administered twice over 12 months to a sample of police service workers and moderated mediation analyses were conducted on the matched sample of $N=2,481$ respondents. The results offer support for the process of occupational stress by demonstrating how both accommodation and avoidance coping mediate the job demands-outcome relationship over time. The results also demonstrate that this stressor-coping-strain process is simultaneously moderated by job support or job control. Interestingly, this research also demonstrated that the estimation of work engagement was not unduly influenced by the type of job demands these police employees were exposed to.
\end{abstract}

Keywords: Job demands, social support, coping, psychological strain, work engagement. 


\section{MODERATED MEDIATION OF STRESS}

\section{Job support, coping, and control: Assessment of simultaneous impacts within the occupational stress process}

Lazarus and Folkman’s (1984) transactional theory of stress and coping provides a widely accepted explanation for the stressor-coping-strain process and remains the cornerstone of psychological stress and coping research across multiple fields (Biggs, Brough, \& Drummond, in press). A basic premise of the transactional model of stress is that the relationship between stressors and strain is primarily influenced by coping responses: "Stress itself pales in significance for adaptation compared with coping... what makes the major difference in adaptation outcomes is coping” (Lazarus, 1998, p. 202). Thus, the mediating influence of coping occurs in response to stressor exposure; that is, the effectiveness of coping in reducing stressor exposure influences experiences of strain. The timespan of this stress-coping-strain process is variable, occurring from hours to years, and empirical support for this transactional process is evident (e.g., O’Driscoll, Brough, \& Kalliath, 2009; Sonnentag \& Fritz, 2015).

The transactional model of psychological stress has informed theoretical explanations for the occurrence of occupational stress, including the job demands control-support (JDC-S) model (Johnson \& Hall, 1988). The JDC-S model describes three key psychosocial job characteristics, which explain the occurrence of occupation stress: psychological demands (typically assessed via measures of job demands), decision latitude (typically assessed via measures of job control), and social support. According to the JDC-S model's strain hypothesis, employees working in jobs characterised by high job demands and low job control/support typically experience high levels of strain. The growth or active learning hypothesis describes how work environments that meet an employee's psychosocial needs for support and control produce positive outcomes, such as individual learning, development, job 


\section{MODERATED MEDIATION OF STRESS}

satisfaction, and high performance. Empirical support for the main effects of the JDC-S model is considerable. For example, jobs characterised by either high job demands, low levels of job control, and low levels of social support are directly associated with a variety of adverse outcomes, including high levels of psychological strain and low levels of work attitudes such as job satisfaction and work engagement (e.g., Brough \& Biggs, 2015; de Jonge, van Vegchel, Shimazu, Schaufeli, \& Dormann, 2010).

Empirical support for the simultaneous experience (interaction) of high job demands and low levels of job control/support is mixed, and the difficulties of producing significant job demands x job control x social support interaction terms have been observed (e.g., Brough et al., 2013; Taris, 2006; van der Doef \& Maes, 1999; Wall, Jackson, Mullarkey, \& Parker, 1996). One explanation for these mixed findings is the specificity of measures employed to assess job demands. It has been demonstrated that including composite measures of generic job demands produces fewer significant job demands $\mathrm{x}$ job control x support interaction terms, as compared to assessments with more focused measures of job demands such as hindrance-challenge demands, cognitive demands, and emotional demands (Daniels, Beesley, Cheyne, \& Wimalasiri, 2008; Mansell \& Brough, 2005). Similarly, the inclusion of occupation-specific job demands has also been associated with more frequent significant demands $\mathrm{x} \mathrm{control/support} \mathrm{interaction} \mathrm{terms} \mathrm{in} \mathrm{assessments} \mathrm{of} \mathrm{specific} \mathrm{workers,} \mathrm{for} \mathrm{example}$ police employees and corrections staff (Brough \& Biggs, 2015; Hart, Wearing, \& Headey, 1995). Recent discussions have also noted the value of assessing 'job resource' variables, such as social support and job control as specific individual indicators, as opposed to a composite latent variable, in assessments of their impact upon the stress-strain relationship (Biggs, Brough, \& Barbour, 2014a; Brough et al., 2013; Luchman \& González-Morales, 2013). 


\section{MODERATED MEDIATION OF STRESS}

In this article we advance existing knowledge of the occupational stress-coping-strain process by identifying where exactly in this process both social support and job control have an impact, as hypothesised by the JDC-S model. We acknowledge that the majority of psychological stress research to date has assessed singular mediating or moderating relationships that occur within either the transactional model of psychological stress or the JDC-S model. This research is valuable but fails to represent the complex reality of stressorstrain processes, especially in terms of assessing its dynamic nature over time. Common third variables within the stressor-strain process such as job control, work support, and coping do not in reality occur independently of one another. Nor do these third variables have an independent moderating and/or mediating impact on the core stressor-strain relationship. Instead, the impact of these third variables often occurs simultaneously, that is, moderating variables, such as job control and social support interact in multiple ways with mediating variables, such as coping, to influence the impact of perceived stressors upon individual outcomes. Simultaneous testing of the impacts of these third variables is rare, which is somewhat surprising, and has significantly limited our knowledge of the specific mechanisms of the occupational stress process.

\section{Cognitive and Emotional Job Demands}

As noted above, the lack of specificity of job demands measures has been discussed as an explanation for difficulties producing significant interactions within assessments of the JDC-S model. Rather than testing generic job demands, this research will examine the specific effects of cognitive and emotional demands, in line with evidence they each uniquely impact psychological outcomes, such as strain and work engagement (e.g., Brough \& Biggs, 2014). The cognitive demands measure utilised in this research focuses on the requirement to pay close attention to work and to engage in problem-solving to complete work tasks.

The largest proportion of occupational stress financial compensatory claims is 


\section{MODERATED MEDIATION OF STRESS}

submitted by workers employed within public service jobs (e.g., Safe Work Australia, 2013). Regular work interactions with people (i.e., customers/clients/the public) can be chronically stressful, especially interactions which are, or have the potential to be, aggressive, violent, and difficult to manage (Brough, O’Driscoll, Kalliath, Cooper, \& Poelmans, 2009). These work encounters are commonly assessed by employee self-reports of emotional job demands, operationalised with measures of emotional dissonance or emotional labour, and defined as the regulation of emotions required by employees in order to successfully perform their job (Kenworthy, Fay, Frame, \& Petree, 2014). More specifically, emotional dissonance is described as a distinct type of emotional regulation and is defined as the requirement for employees to express emotions that are not genuinely felt in a situation (Zapf, Vogt, Seifert, Mertini, \& Isic, 1999).

In an interesting comparison of general (quantitative) job demands and emotional job demands, van Vegchel, de Jonge, Söderfeldt, Dormann, and Schaufeli (2004, p. 21) concluded that "emotional demands are as important as, and sometimes more important than, quantitative demands in human service work.” Emotional job demands have been demonstrated to have significant negative consequences for the levels of psychological strain, health problems, and work attitudes experienced by multiple samples of public service workers including: nurses and healthcare workers (de Jonge, Le Blanc, Peeters, \& Noordam, 2008), fire-fighters (Tuckey \& Hayward, 2011), police officers (Brough, Chataway, \& Biggs, 2016; van Gelderen, Heuven, van Veldhoven, Zeelenberg, \& Croon, 2007), finance workers (Schaufeli \& Bakker, 2004), airline staff and retail workers (Giardini \& Frese, 2006; Zapf et al., 1999). Strong justification thus exists for the inclusion of emotional job demands in the assessment of occupational stress within samples of human service workers.

In terms of the relationships between cognitive and emotional job demands with psychological outcomes, evidence suggests there are positive associations between cognitive 


\section{MODERATED MEDIATION OF STRESS}

job demands and work engagement (e.g., Van den Broeck, De Cuyper, De Witte, \& Vansteenkiste, 2010), and between emotional job demands and psychological illhealth (e.g., Luchman \& Gonzáles-Morales, 2013). It appears to be the case that the focus of cognitive job demands (e.g., problem-solving) is closely aligned to the active learning hypothesis of occupational stress models described by the JDC-S and is, therefore, positively associated with work-specific outcomes such as work engagement. Thus, motivation and engagement are produced when mastery of these cognitive job demands occurs. In contrast, emotional job demands cannot be so easily 'mastered' and are instead perceived to be negative energydepleting demands. Emotional job demands are therefore, more strongly associated with the strain hypothesis of the JDC-S and with psychological strain/burnout outcomes (Luchman \& González-Morales, 2013).

\section{Role of Coping}

In accordance with the transactional model of stress (Lazarus \& Folkman, 1984), coping responses to emotional and cognitive demands are assessed in this research. The theoretical framework of coping behaviours adopted by this research is informed by Edwards' (1998) cybernetic theory of stress, coping and well-being. Edwards' (1998) cybernetic theory, similar to Lazarus and Folkman’s (1984) transactional stress theory, describes stress, coping, and well-being as interacting elements between the individual and their environment, where stressors result in some form of imbalance (strain) in the individual's level of equilibrium (well-being). Attempts to correct (mediate) this equilibrium, usually in connection with environmental interaction and/or learning experiences, are categorized as coping behaviors. Edwards and Baglioni (1993) conceptualised coping as consisting of five commonly occurring behaviors: change the situation, accommodation, devaluation, avoidance, and symptom reduction. This contrasts with the transactional model of stress, which primarily describes a dual (problem-focused and emotion-focused) coping 


\section{MODERATED MEDIATION OF STRESS}

taxonomy. Edwards and Baglioni’s (1993) five-factor structure of coping has been successfully replicated in multiple samples (e.g., Brough, O'Driscoll, \& Kalliath, 2005) and is adopted within the current research.

\section{Impact of Support and Control within the Occupational Stress Process}

The stress-coping-strain process described by the transactional model of stress produces three pathways all of which could theoretically be moderated by social support and/or job control (see Figure 1). Path ' $a$ ' represents the relationship between job demands and coping; path ' $b$ ' represents the relationship between coping and psychological outcomes (in this case psychological strain and work engagement); and path ' $c$ ' represents the direct relationship between job demands and psychological outcomes. However, only the two paths ' $a$ ' and ' $b$ ' include an assessment of coping as a mediator of the stress-strain reaction. The moderation of social support and/or job control on these two pathways ' $a$ ' and ' $b$ ', in combination with mediation by coping, is therefore the focus of this research, in order to assess the simultaneous moderated mediation of the stress-strain process.

\section{INSERT FIGURE 1 ABOUT HERE}

Whilst theoretically feasible, minimal evidence for the ability of social support and/or job control to moderate the association between job demands and coping responses (path ' $a$ ') or the association between coping and psychological outcomes (path ' $b$ ') currently exists. Reasons for this scarcity are not clear. One explanation for this scarcity may be that social support is often treated as a coping resource in examining relationships with wellbeing outcomes. For example, the findings of Kirmeyer and Dougherty (1988) offer some evidence for the moderation of job demands by support in the prediction of coping (path ' $a$ '). Kirmeyer and Dougherty reported that US police dispatchers with high workloads and high levels of supervisor support reported more "extensive” coping behaviours, compared to dispatchers 


\section{MODERATED MEDIATION OF STRESS}

with low support. Similarly, Bal, Crombez, Van Oost, and Debourdeaudhuij (2003) also observed an impact upon the use of coping behaviours by adolescents who reported a stressful event and who received high levels of support. Evidence that social support moderates the association between coping behaviours and psychological outcomes (path ' $b$ ') was reported by Lengua and Sandler (1996) in a study of children of divorce.

Other research has adopted different techniques to assess the impact of coping within the JDC-S model. For example, Daniels (1999) tested the moderating impact of three-way interaction terms composed of coping, job control and social support upon psychological wellbeing and found that in certain conditions control and support enhanced coping behaviours. However, Daniels (1999) also noted the low proportions of variance (maximum of 3\%) accounted for by these analyses, suggesting that the combined impact of coping, job control and social support upon wellbeing was extremely low. More recently, Daniels et al. (2008) combined coping behaviours directly with social support and job control in the questions asked of a sample of nuclear engineers to predict levels of wellbeing, fatigue, and risky decision-making. The authors reported that coping (problem-focused or emotionalfocused) was influenced by control and support in specific combinations to impact the outcomes. As their investigation was designed as a diary study, Daniels et al. (2008) demonstrated in part the dynamic processes of the JDC-S model and identified the need to conduct further temporal assessments to ascertain the cycles of employee's health and wellbeing.

\section{The Current Research}

Limited research to date has empirically integrated the transactional model of stress and the JDC-S to explain how work-related resources impact the mediation of coping upon the associations between work demands and psychological outcomes. The current research aims to rectify this omission by integrating both the transactional theory of stress and the 


\section{MODERATED MEDIATION OF STRESS}

JDC-S explanation of occupational stress in one assessment of how two categories of job demands (challenge demands and emotional demands) impact upon a work-specific outcome (work engagement) and a context-free mental health outcome (psychological strain), within a sample of 'high-risk' of stress public service workers (police service employees). Thus the current research assesses the impact of coping as a mediating variable upon the stress-strain process (as proscribed by the transactional theory of stress; Lazarus \& Folkman, 1984) whilst simultaneously assessing the moderating impact of social support and job control upon this stress-coping-strain relationship (as proposed by the JDC-S explanation of occupational stress; Johnson \& Hall, 1988). To test the simultaneous influence of the moderating variables (support and coping) upon the mediated stress-coping-strain relationship, two points of moderation are assessed: path ' $a$ ' (demands to coping) and path ' $b$ ' (coping to outcomes) and this hypthoesed model is illustrated in Figure 1. This research, therefore, contributes to theoretical discussions by assessing the degree by which each type of job demands predicts each psychological outcome, whilst simultaneously being mediated by coping and moderated by both job control and social support. Following the theoretical tenants of both the transactional model of stress and the JDC-S model and the reported evidence from the literature, we assess two research hypotheses:

Hypothesis 1: Cognitive job demands will have a positive impact upon the two psychological outcomes over time (i.e., a negative association with psychological strain and a positive association with work engagement) via coping, and this relationship will be moderated by job control and/or supervisor support.

Hypothesis 2: Emotional job demands will have a negative impact upon the two psychological outcomes over time (i.e., a positive association with psychological strain and a negative association with work engagement) via coping, and this relationship will be moderated by job control and/or supervisor support. 


\section{MODERATED MEDIATION OF STRESS}

\section{Method}

\section{Procedure and Participants}

This research received human research ethics approval from both the respective university (GU Ref No: PSY/20/08/HREC) and organization research ethics committees. Two electronic self-report questionnaires were distributed to all police service employees of one Australian state police service via email. A 12-month lag occurred between the survey administrations primarily for reasons of organisational preference but also in consideration of discussions advocating for a suitable passage of time between surveys to enable any changes in the criterion variables to reasonably occur (e.g., Dormann \& Griffin, 2015). Responses across the two waves of data collection were matched based on individual respondents' email addresses. A total of $N=2,481$ usable matched responses were received for both the Time 1 and Time 2 surveys, producing a response rate of approximately 53\%. The majority of respondents were male ( $n=1,555 ; 62 \%)$, ranging in age from 20 to 71 years $(M=41.21, S D$ =9.09), had completed at least a diploma-level certificate ( $n=1,624 ; 65 \%)$, and had been employed for an average of 13 years $(S D=9.97)$. The majority of respondents were employed full-time ( $n=2,347 ; 94 \%)$, were sworn police officers ( $n=1,647 ; 66 \%)$, and worked an average of 41 hours per week $(S D=9.06)$. Of the respondent police officers who specified their rank the majority were constables and senior constables ( $n=835$; 33.7\%) or sergeants and senior sergeants $(n=674 ; 27.2 \%)$. Only $n=128(5.2 \%)$ respondents indicated they were commissioned officers (i.e., inspectors and above).

\section{Measures}

Cognitive job demands and job control. Wall, Jackson, and Mullarkey’s (1995) 19item job characteristics measure was used to assess job control and two types of cognitive job demands. The cognitive job demands scale was comprised of two subscales - monitoring demands (four items; “Does your work need your undivided attention?”) and problem-solving 


\section{MODERATED MEDIATION OF STRESS}

demands (five items; "Do you have to solve problems which have no obvious correct answer?”), while the job control scale consisted of 10 items (e.g., “Do you decide on the order in which you do things?”). All items were rated on a 5-point scale (1 = not at all and 5 = a great deal), such that high scores indicated high levels of demands and job control. All scales demonstrated acceptable reliability coefficients: monitoring demands ( $\alpha=.79$ ), problem-solving demands $(\alpha=.86)$, and job control $(\alpha=.94)$.

Emotional dissonance. Zapf et al’s (1999) 5-item emotional dissonance measure was included to assess emotional job demands. An example item is "Show emotions that do not agree with your true feelings?” with responses scored on a 5-point scale from 1 (very rarely/never) to 5 (very often - several times an hour). High scores indicate high levels of emotional dissonance. The scale demonstrated an acceptable reliability (Cronbach’s alpha) of .93 .

Supervisor support. Supervisor support was assessed with four items from Caplan, Cobb, French, Harrison, and Pinneau’s (1980) social support scale. An example item is “How easy is it to discuss your problems with your immediate supervisor?” Responses were recorded on a 5-point scale ( 1 = don't have such a person and $5=$ very much), with high scores indicating high levels of work support. The subscale demonstrated a high internal reliability of (Cronbach’s alpha) .92.

Coping. Brough et al.’s (2005) revised 14-item version of Edwards and Baglioni’s (1993) Cybernetic Coping Scale (CCS) was used to assess a range of coping responses. The CCS assesses common generic (trait-like) coping behaviors at work and is not, therefore, associated with any specific situation. The respondents were directed to indicate how often they used each item to help them cope with their general work stress. The scale consists of five subscales: change the situation (two items; "I try to change the situation to get what I want”); accommodation (two items; "I make an effort to change my expectations”); 


\section{MODERATED MEDIATION OF STRESS}

devaluation (four items; "I try to convince myself that the problem is not important after all”); avoidance (four items; “I try to keep myself from thinking about the problem”); and symptom reduction (two items; “I try to just let off steam”). Responses were scored on a 7point scale from 1 (never use) to 7 (use very often), with high scores indicating high levels of coping. The five coping subscales demonstrated acceptable reliability (Cronbach’s alpha), ranging from .69 (symptom reduction) to .90 (devaluation).

Work engagement. Engagement was measured with the 9-item Utrecht Work Engagement Scale (Schaufeli, Bakker, \& Salanova, 2006). An example item is: "When I get up in the morning, I feel like going to work.” Participants responded on a 7-point scale $(0=$ never and 6 = every day), such that high scores indicated high levels of work engagement. The scale demonstrated high levels of internal reliability (Cronbach's alpha) across both time points: .92 (Time 1) and .93 (Time 2).

Psychological strain. Psychological strain was assessed with Goldberg’s (1972) 12item General Health Questionnaire (GHQ). Respondents indicated their recent experiences of, for example, “Been feeling unhappy or depressed” in the past few weeks, and were scored on a 4-point scale from 0 (not at all) to 3 (much more than usual). High scores represent high levels of psychological strain. Reliability coefficients were calculated as .91 at both Time 1 and Time 2.

Demographic variables. Key demographic information was also collected from the respondents. Gender was dummy coded $0=$ male and $1=$ female. Job type was coded $1=$ police officers and 2 = civilian employees.

\section{Statistical Analyses}

The moderated mediation model (Figure 1) was tested with emotional job demands and the two types of cognitive job demands as the Time 1 predictor variables, the five coping subscales (Time 1) as the mediators, and psychological strain and work engagement (Time 2) 


\section{MODERATED MEDIATION OF STRESS}

as the criterion variables. Time 1 supervisor support and job control were included as the moderators on the two paths in each model from predictors to outcomes variables. The Time 1 dependent variables were also included as covariates in this model. The models were analysed with the PROCESS macro (Hayes, 2012) in SPSS version 21. This macro enables the testing of relationships involving a combination of mediation and moderation using bootstrapped estimates and bias corrected confidence intervals to assess significance. For each analysis, variables were mean centred, analyses were conducted with 5,000 bootstrap samples, and 95\% bias corrected confidence intervals and heteroscedastic-consistent standard errors (HSE) were employed. Where significant effects were found for only one moderator and/or mediator, the analysis was performed again with the non-significant variables included as covariates, to enable interpretation of the results.

\section{Results}

\section{Descriptive Results}

The means, standard deviations, and bivariate correlations between the research variables are presented in Table 1 . As expected, significant relationships were observed between the predictor variables (job demands, supervisor support, and job control) and the criterion variables (work engagement and psychological strain) at both Time 1 and Time 2. The five coping subscales were generally positively correlated with measures of job demands, suggesting higher levels of job demands were associated with higher levels of coping. The three coping styles of devaluation, avoidance, and symptom reduction were each positively associated with psychological strain and negatively associated with work engagement at both Time 1 and Time 2. Gender and job type (police officers or civilian employees) also demonstrated significant relationships with the research variables and therefore, have been included as covariates within the subsequent analyses, along with the respective Time 1 dependent variable. 


\section{MODERATED MEDIATION OF STRESS}

\section{INSERT TABLE 1 ABOUT HERE}

\section{Moderated Mediation for Cognitive Demands}

For the test of Hypothesis 1, the results revealed significant moderated mediation effects for cognitive job demands in the prediction of work engagement and psychological strain, over time. Table 2 demonstrates that both types of cognitive job demands increased levels of work engagement by increasing accommodation coping for employees with low levels of supervisor support. These results suggest that when employees have low levels of supervisor support, the use of accommodation coping can be effective in increasing work engagement. Table 2 also demonstrates that monitoring demands increased psychological strain by increasing avoidance coping for employees with low levels of support. This result suggests that when employees have low levels of supervisor support, the demands of job tasks requiring monitoring can lead to increased use of avoidance coping to manage the demands, which in turn increases feelings of psychological strain. The results for predicting work engagement support Hypothesis 1, however the result for psychological strain is contrary to the expected direction, producing only partial support for Hypothesis 1.

\section{INSERT TABLE 2 ABOUT HERE}

\section{Moderated Mediation for Emotional Demands}

For the test of Hypothesis 2, the results revealed significant moderated mediation effects for emotional demands in the prediction of work engagement but not psychological strain over time; however the effects were in the opposite direction to that which was hypothesised. Table 3 demonstrates that emotional dissonance increased work engagement through two different mechanisms. First, similar to cognitive demands, emotional dissonance increased work engagement by increasing the use of accommodation coping for employees with low levels of supervisor support. This result is consistent with the result above for cognitive demands, thereby suggesting that both cognitive and emotional job demands are 


\section{MODERATED MEDIATION OF STRESS}

similar in their impact on work engagement when they increase accommodation coping for employees experiencing low levels of supervisor support.

Second, in conditions of increasing levels of job control, emotional demands increased work engagement through the use of accommodation coping. This effect suggests that emotional demands can increase accommodation coping regardless of the level of job control. However, this effect is stronger with higher levels of control, as evidenced by significant indirect effects at each level of the moderator in Table 3. Together, these significant effects offer partial support for Hypothesis 2 as the results were in the opposite direction to what was expected. Finally, the lack of significant moderated mediation results for the prediction of psychological strain offers only partial support for Hypothesis 2.

\section{INSERT TABLE 3 ABOUT HERE}

\section{Discussion}

This research assessed two key issues identified in the literature regarding the mixed results pertaining to the JDC-S model's explanation of occupational stress: the use of specific measures of job demands, and the influence of third variables (i.e., coping). The results demonstrated that: (a) cognitive job demands and emotional job demands operate differently in the prediction of work engagement and psychological strain, revealing that the type of job demand is indeed important to consider in assessments of employee's job attitudes and health outcomes, and (b) including coping as a third variable in the job demands-control-support relationship revealed complex relationships in the way job demands impact work and nonwork outcomes. The testing of the relationships between these variables by simultaneous moderated mediation analyses was successfully demonstrated, providing evidence for the effectiveness of this method of analysis in the assessment of occupational stress. An additional finding that has relevance for the JDC-S literature was that the role of supervisor 


\section{MODERATED MEDIATION OF STRESS}

support as a moderator of the mediated stress-coping-outcome process was evident, while less evidence was produced for the moderating role of job control.

\section{Differentiating Between Types of Job Demands}

The results clearly demonstrated that cognitive job demands and emotional job demands operate differently in the prediction of work engagement and psychological strain when their effects are investigated through third variables. First, work engagement was predicted by both cognitive and emotional job demands, whereas psychological strain was only predicted by cognitive job demands. Interestingly, both types of job demands had beneficial outcomes on work engagement, contrary to Hypothesis 2 that predicted emotional job demands would have detrimental impacts on the outcome variables.

The second result that demonstrates the differences in cognitive and emotional job demands is that the relationship between the type of job demand and coping differs for work engagement and psychological strain. In the prediction of work engagement, both types of job demands predicted work engagement through accommodation coping in the same way, that is, by increasing levels of work engagement. However, in the prediction of psychological strain, only cognitive job demands predicted strain through avoidance coping. Therefore, the type of job demand does not influence the effect of accommodation coping on work engagement, suggesting the use of accommodation coping in situations with low supervisor support, regardless of type of job demand, can result in positive work engagement outcomes. For psychological strain, these results imply that employees in passive jobs (low levels of both cognitive demands and social support) use avoidance coping to manage their psychological health outcomes. This point has previously been observed; where neither the job content nor the job resources can be readily changed then employees may ignore the situation and/or engage in distracting activities (avoidance) in order to manage their work 


\section{MODERATED MEDIATION OF STRESS}

experiences (e.g., Dewe, O’Driscoll, \& Cooper, 2010), which ultimately leads to increased psychological strain in the long term.

\section{Coping}

The second issue addressed by this research was the influence of coping in understanding the interactions between job control, supervisor support, and job demands. A key finding was that job demands led to increased levels of work engagement by evoking coping, suggesting that conditions of low support or control can still lead to beneficial outcomes when coping behaviors are undertaken. For example, both cognitive and emotional job demands increased work engagement over time by increasing accommodation coping for employees with low supervisor support. Similarly, emotional job demands increased work engagement over time by increasing accommodation coping for employees with low levels of job control. These results demonstrate that conditions of low support and control can be associated with beneficial outcomes when coping is taken into consideration; thus coping is an important strategy for ameliorating the negative effects of job demands on outcomes when levels of supervisor support and control are deficient. This finding supports previous observations that high job demands coupled with low support and high problem-focused coping is associated with increased well-being (e.g., Daniels et al., 2008; Dewe et al., 2010). The results also suggest that employees with low levels of supervisor support may recognize this deficit and instigate the use of problem-focused coping strategies to manage their emotional demands, leading to beneficial outcomes. This suggestion has intuitive value but requires further consideration, particularly in terms of theoretical explanations of how resource gains and losses occur via compound, rather than compensation, processes (Hobfoll \& Shirom, 1993).

\section{Limitations and Future Directions}




\section{MODERATED MEDIATION OF STRESS}

One research limitation is the assessment of coping only as mediating variable (in accordance with the transactional stress-coping-strain process) and not also as a potential moderating variable. We acknowledge the evidence indicating that coping can reduce the associations between job demands and psychological outcome variables via a moderating influence (e.g., Frese, 1986; Osipow \& Davis, 1988; Siu, Spector, Cooper, Lu, \& Yu, 2002), although this finding also appears to be dependent upon the specific independent variable assessed. Nevertheless, we acknowledge that an alternative model assessing coping as a moderating variable impacting the stress-strain process is worthy of consideration, although we note this would not directly contribute to knowledge in terms of assessing the JDC-S and transactional models simultaneously.

It is important to ascertain the extent to which the results presented here are due to specific cohort effects. To what degree are these results generalizable to other human service workers? We note that our results concerning the impact of social support within the stresscoping-strain process does support previous research conducted with both police (e.g., Brough \& Biggs, 2010; Kirmeyer \& Dougherty, 1988) and non-police human service employee samples (e.g., Bal et al., 2003; Daniels et al., 2008). We also acknowledge that approximately one third of our sample (34\%) consisted of civilian police employees, representing more 'generic' human service workers as compared to sworn police officers. Controlling for this job type (police officer or civilian employee) within these analyses did have an impact upon the results, especially in terms of the non-significant impact of emotional dissonance upon (police officer’s) experiences of psychological strain (e.g., Brough et al., 2016; van Gelderen et al., 2007). We also acknowledge that the sample of police officers who responded to this research were primarily from the lower ranks (constables and senior constables). We acknowledge that replication with a sample of police officers with a greater variation of police ranks would be valuable, in order to specifically test 


\section{MODERATED MEDIATION OF STRESS}

for any impact of police officer rank upon perceptions of job control especially. Nevertheless, we note that the simultaneous impacts of social support and job control upon this mediated stress-coping-strain process requires replication in non-police samples to strengthen the theoretical implications produced by the current research.

Meaningful advances in theoretical explanations of occupational stress have been hampered to an extent by the use of conservative research designs (e.g., dominance of crosssectional designs), research sampling biases (e.g., dominance of small Western samples), and minute variations of research variables (e.g., testing multiple types of job resources). These considerations are recognised as contributing to stagnation in significant scholarly developments in this field (e.g., Brough, Brown, \& Biggs, 2016; Brough et al., 2009). Recent technological developments have provided researchers with increased opportunities to adopt innovative approaches to theory-testing and development, including easier administrations to large research samples, inclusion of longitudinal data collection techniques, and the availability of statistical software enabling comparisons of both multi-national samples and complex research models (e.g., Biggs, Brough, \& Barbour, 2014b; Drummond, O’Driscoll, Brough, Kalliath, Siu, Timms, et al., 2016). As demonstrated by the current research, it is anticipated that these technological developments will enable further enlightenment of theoretical conundrums evident for several decades.

The impact of job demands, social support, job control and coping behaviours upon employee health and work performance have a substantial history of research and the 'problem' of insufficient empirical evidence of the interactions between these variables is a long standing issue (e.g., Daniels, Boocock, Glover, Hartley, \& Holland, 2009; de Lange, Taris, Kompier, Houtman, \& Bongers, 2003). The current research illustrates that discussions of appropriate construct assessments are indeed pertinent and the importance therefore, of including measures which actually represent the common experiences of the sampled 


\section{MODERATED MEDIATION OF STRESS}

workers. As opposed to assessments which rely upon generalised measures deemed to represent the experiences of ‘average’ employees (Biggs \& Brough, 2017; Brough \& Biggs, 2014). Similarly, the current research also supports discussions recommending the analysis of the individual measures of job demands and job resources respectively, within tests of theoretical explanations of occupational stress (e.g., Luchman \& González-Morales, 2013), as opposed to analyses primarily based on combining constructs (i.e., latent variables). It is difficult to understand how advances in knowledge can readily be forged with the use of methodological techniques based primarily upon broad groupings of employee’s work characteristics.

\section{Conclusions}

This paper provided a rare test of simultaneous moderated mediation analyses within the longitudinal process of occupational stress. The research successfully demonstrated that multiple moderating and mediating variables can be simultaneously assessed, thereby providing an improved representation of the 'reality’ of occupational stress and improving our ability to empirically assess theoretical explanations of this stress process. This research offers support for the process of occupational stress by demonstrating how coping behaviours mediate the job demands-outcome relationship over time (i.e., the transactional stress model; Lazarus \& Folkman, 1984). This research also advances discussions by demonstrating that this stressor-coping-strain process is simultaneously moderated by job support or job control, resulting in improved outcomes over time (i.e., the JDC-S model; Johnson \& Hall, 1988). Interestingly, this research also demonstrated that the estimation of work attitudes (work engagement) was not unduly influenced by the type of job demands these police employees were exposed to, which warrants further investigation.

\section{References}




\section{MODERATED MEDIATION OF STRESS}

Safe Work Australia. (2013). The incidence of accepted workers compensation claims for mental stress in Australia (Publication No. 978-0-642-78719-4). Retrieved from http://www.safeworkaustralia.gov.au:

Bal, S., Crombez, G., Van Oost, P., \& Debourdeaudhuij, I. (2003). The role of social support in well-being and coping with self-reported stressful events in adolescents. Child Abuse \& Neglect, 27(12), 1377-1395. doi: 10.1016/j.chiabu.2003.06.002

Biggs, A., \& Brough, P. (2017). Effects of police culture and support on work and non-work outcomes. Chapter in: R Burke (Editor). Stress in policing: Sources, consequences, and interventions. (pp. 309-322). Taylor \& Francis Ltd: London, UK

Biggs, A., Brough, P., \& Barbour, J. P. (2014a). Relationships of individual and organizational support with engagement: Examining various types of causality in a three-wave study. Work \& Stress, 28, 236-254. doi: 10.1080/02678373.2014.934316

Biggs, A., Brough, P., \& Barbour, J. P. (2014b). Enhancing work-related attitudes and work engagement: A quasi-experimental study of the impact of an organizational intervention. International Journal of Stress Management, 21, 43-68. doi:10.1037/a0034508

Biggs, A., Brough, P., \& Drummond, S. (in press). Lazarus and Folkman’s psychological stress and coping theory. In C. L. Cooper \& J. Quick. (Eds.), The Wiley handbook of stress and health: A guide to research and practice. London: Wiley.

Brough, P., \& Biggs, A. (2010). Occupational stress in police and prison staff. In J. Brown \& E. Campbell (Eds.), The Cambridge handbook of forensic psychology (pp. 707-718). Cambridge, UK: Cambridge University Press.

Brough, P., \& Biggs, A. (2014). Comparing the impact of occupation-specific and generic work characteristics. In: Dollard, M., Shimazu, A., Bin Nordin, R., Brough, P., \& 


\section{MODERATED MEDIATION OF STRESS}

Tuckey, M. (Editors). Psychosocial factors at work in the Asia Pacific. (pp. 145-159). London, UK: Springer.

Brough, P., \& Biggs, A. (2015). Job demands x job control interaction effects: Do occupation-specific job demands increase their occurrence? Stress \& Health, 31(2), 138-149. doi:10.1002/smi.2537

Brough, P., Brown, J., \& Biggs, A. (2016). Improving criminal justice workplaces:

Translating theory and research into evidenced-based practice. London: Routledge. Brough, P., Chataway, S., \& Biggs, A. (2016). “You don’t want people knowing you’re a copper!” A contemporary assessment of police organisational culture. International Journal of Police Science \& Management, 18, 28-36. doi:

\section{$10.1177 / 1461355716638361$}

Brough, P., O'Driscoll, M., \& Kalliath, T. (2005). Confirmatory factor analysis of the Cybernetic Coping Scale. Journal of Occupational and Organisational Psychology, 78, 53-61. doi:10.1348/096317904X23754

Brough, P., O’Driscoll, M., Kalliath, T., Cooper, C. L., \& Poelmans, S. (2009). Workplace psychological health: Current research and practice. Cheltenham, UK: Edward Elgar.

Brough, P., Timms, C., Siu, O. L., Kalliath, T., O’Driscoll, M., Sit, C., . . Lu, C. Q. (2013). Validation of the job demands-resources model in cross-national samples: Crosssectional and longitudinal predictions of psychological strain and work engagement. Human Relations, 66, 1311-1335. doi:10.1177/0018726712472915

Caplan, R. D., Cobb, S., French, J. R. P. J., Harrison, R. V., \& Pinneau, S. R. (1980). Job Demands and Worker Health: Main Effects and Occupational Differences. Ann Arbour, MN: Institute for Social Research. 


\section{MODERATED MEDIATION OF STRESS}

Daniels, K. (1999). Coping and the job demands-control-support model: An exploratory study. International Journal of Stress Management, 6, 125-144.

Daniels, K., Beesley, N., Cheyne, A., \& Wimalasiri, V. (2008). Coping processes linking the demands-contorl-support model, affect and risky decisons at work. Human Relations, 61, 845-874. doi:10.1177/0018726708093543

Daniels, K., Boocock, G., Glover, J., Hartley, R., \& Holland, J. (2009). An experience sampling study of learning, affect, and the demands control support model. Journal of Applied Psychology, 94, 1003-1017. doi: 10.1037/a0015517

de Jonge, J., Le Blanc, P. M., Peeters, M. C. W., \& Noordam, H. (2008). Emotional job demands and the role of matching job resources: A cross-sectional survey study among health care workers. International Journal of Nursing Studies, 45, 1460-1469. doi: 10.1016/j.ijnurstu.2007.11.002

de Jonge, J., van Vegchel, N., Shimazu, A., Schaufeli, W., \& Dormann, C. (2010). A longitudinal test of the demand-control model using specific job demands and specific job control. International Journal of Behavioral Medicine, 17, 125-133. doi:10.1007/s12529-010-9081-1

de Lange, A. H., Taris, T. W., Kompier, M. A., Houtman, I. L., \& Bongers, P. M. (2003). “The very best of the millennium”: Longitudinal research and the demand-control(support) model. Journal of Occupational Health Psychology, (4), 282-305.

Dewe, P., O’Driscoll, M., \& Cooper, C. L. (2010). Coping with work stress: A review and critique. Chichester: Wiley Blackwell.

Dormann, C., \& Griffin, M. A. (2015). Optimal time lags in panel studies. Psychological Methods, 20(4), 489-505. doi: 10.1037/met0000041

Drummond, S., O’Driscoll, M. P., Brough, P., Kalliath, T., Siu, O.-L., Timms, C....Lo, D. (2016). The relationship of social support with well-being outcomes via work-family 


\section{MODERATED MEDIATION OF STRESS}

conflict: Moderating effects of gender, dependants and nationality. Human Relations, 1-22. doi: 10.1177/0018726716662696

Edwards, J. R. (1998). Cybernetic theory of stress, coping, and well-being. In C. L. Cooper (Ed.), Theories of Organizational Stress (pp. 122-152). Oxford: Oxford University Press.

Edwards, J. R., \& Baglioni, A. J. J. (1993). The measurement of coping with stress: Construct validity of the Ways of Coping Checklist \& the Cybernetic Coping Scale. Work \& Stress, 7(1), 17-31. doi: 10.1080/02678379308257047

Frese, M. (1986). Coping as a moderator and mediator between stress at work and psychosomatic complaints. In Dynamics of stress (pp. 183-206). Springer US.

Giardini, A., \& Frese, M. (2006). Reducing the negative effects of emotion work in service occupations: Emotional competence as a psychological resource. Journal of Occupational Health Psychology, 11(1), 63-75. doi: 10.1037/1076-8998.11.1.63

Goldberg, D. P. (1972). The Detection of Psychiatric Illness by Questionnaire. Oxford: Oxford University Press.

Hart, P. M., Wearing, A. J., \& Headey, B. (1995). Police stress and well-being: Integrating personality, coping and daily work experiences. Journal of Occupational \& Organisational Psychology, 68(2), 133-156. doi: 10.1111/j.20448325.1995.tb00578.x

Hayes, A. F. (2012). PROCESS: A versatile computational tool for observed variable mediation, moderation, and conditional process modelling. Retrieved from http://www.afhayes.com/public/process2012.pdf website:

Hobfoll, S., \& Shirom, A. (1993). Stress and burnout in the workplace. In R. Golembiewski (Ed.), Handbook of organizational behavior (pp. 41-60). New York: Marcel Dekker. 


\section{MODERATED MEDIATION OF STRESS}

Johnson, J., \& Hall, E. (1988). Job strain, work place social support and cardiovascular disease: A cross-sectional study of a random sample of the working population. American Journal of Public Health, 78(10), 1336-1342. doi: 10.2105/ajph.78.10.1336

Kenworthy, J., Fay, C., Frame, M., \& Petree, R. (2014). A meta-analytic review of the relationship between emotional dissonance and emotional exhaustion. Journal of Applied Social Psychology, 44(2), 94-105. doi: 10.1111/jasp.12211

Kirmeyer, S. L., \& Dougherty, T. W. (1988). Work load, tension, and coping: Moderating effects of supervisor support. Personnel Psychology, 41(1), 125-139. doi: 10.1111/j.1744-6570.1988.tb00635.x

Lazarus, R. S. (1998). Fifty years of the research and theory of RS Lazarus: An analysis of historical and perennial issues. London, UK: Routledge.

Lazarus, R. S., \& Folkman, S. (1984). Stress, appraisal, and coping. New York: Springer Publishing, Inc.

Lengua, L. J., \& Sandler, I. N. (1996). Self-regulation as a moderator of the relation between coping and symptomatology in children of divorce. Journal of Abnormal Child Psychology, 24(6), 681-701. doi: 10.1007/bf01664734

Luchman, J. N., \& González-Morales, M. G. (2013). Demands, control, and support: A metaanalytic review of work characteristics interrelationships. Journal of Occupational Health Psychology, 18(1), 37-52. doi: 10.1037/a0030541

Mansell, A., \& Brough, P. (2005). A comprehensive test of the job demands-control interaction: Comparing two measures of job characteristics. Australian Journal of Psychology, 57, 103-114. doi:10.1080/10519990500048579

O’Driscoll, M., Brough, P., \& Kalliath, T. (2009). Stress and coping. In S. Cartwright \& C. L. Cooper (Eds.), The Oxford handbook of organizational well being (pp. 237-266). Oxford: Oxford University Press. 


\section{MODERATED MEDIATION OF STRESS}

Osipow, S. H., \& Davis, A. S. (1988). The relationship of coping resources to occupational stress and strain. Journal of Vocational Behavior, 32, 1-15.

Schaufeli, W. B., \& Bakker, A. B. (2004). Job demands, job resources, and their relationship with burnout and engagement: A multi-sample study. Journal of Organizational Behavior, 25(3), 293-315. doi: 10.1002/job.248

Schaufeli, W. B., Bakker, A. B., \& Salanova, M. (2006). The measurement of work engagement with a short questionnaire: A cross-national study. Educational and Psychological Measurement, 66, 701-716. doi:10.1177/0013164405282471

Siu, O. L., Spector, P. E., Cooper, C. L., Lu, L., \& Yu, S. (2002). Managerial stress in greater China: The direct and moderator effects of coping strategies and work locus of control. Applied Psychology, 51, 608-632.

Solberg, E., \& Wong, S. I. (in press). Crafting one's job to take charge of role overload: When proactivity requires adaptivity across levels. The Leadership Quarterly.

Sonnentag, S., \& Fritz, C. (2015). Recovery from job stress: The stressor-detachment model as an integrative framework. Journal of Organizational Behavior, 36(S1), S72-S103. doi: 10.1002/job.1924

Taris, T. W. (2006). Commentary: Bricks without clay: On urban myths in occupational health psychology. Work \& Stress, 20(2), 99-104. doi: 10.1080/02678370600893410

Tuckey, M. R., \& Hayward, R. (2011). Global and occupation-specific emotional resources as buffers against the emotional demands of fire-fighting. Applied Psychology: An International Review, 60, 1-23. doi:10.1111/j.1464-0597.2010.00424.x

Van den Broeck, A., De Cuyper, N., De Witte, H., \& Vansteenkiste, M. (2010). Not all job demands are equal: Differentiating job hindrances and job challenges in the Job Demands-Resources model. European Journal of Work and Organizational Psychology, 19(6), 735-759. doi: 10.1080/13594320903223839 


\section{MODERATED MEDIATION OF STRESS}

van der Doef, M., \& Maes, S. (1999). The job demand-control(-support) model and psychological well-being: a review of 20 years of empirical research. Work \& Stress, 13(2), 87-114. doi: 10.1080/026783799296084

van Gelderen, B., Heuven, E., van Veldhoven, M., Zeelenberg, M., \& Croon, M. (2007).

Psychological strain and emotional labor among police-officers: A diary study. Journal of Vocational Behavior, 71(3), 446-459. doi: 10.1016/j.jvb.2007.09.001

van Vegchel, N., de Jonge, J., Söderfeldt, M., Dormann, C., \& Schaufeli, W. (2004).

Quantitative versus emotional demands among Swedish human service employees:

moderating effects of job control and social support. International Journal of Stress Management, 11(1), 21-40. doi: 10.1037/1072-5245.11.1.21

Wall, T. D., Jackson, P. R., \& Mullarkey, S. (1995). Further evidence on some new measures of job control, cognitive demand, and production responsibility. Journal of Organizational Behavior, 16(5), 431-455. doi: 10.1002/job.4030160505

Wall, T. D., Jackson, P. R., Mullarkey, S., \& Parker, S. K. (1996). The demands-control model of job strain: A more specific test. Journal of Occupational and Organizational Psychology, 69(2), 153-166. doi:10.1111/j.2044-8325.1996.tb00607.x

Zapf, D., Vogt, C., Seifert, C., Mertini, H., \& Isic, A. (1999). Emotion work as a source of stress: The concept and development of an instrument. European Journal of Work and Organizational Psychology, 8(3), 371-400. doi: 10.1080/135943299398230 
Table 1. Descriptive statistics for the research variables

\begin{tabular}{|c|c|c|c|c|c|c|c|c|c|c|c|c|c|c|c|c|}
\hline & 1. & 2. & 3. & 4. & 5. & 6. & 7. & 8. & 9. & 10. & 11. & 12. & 13. & 14. & 15. & 16. \\
\hline 1. Gender & - & & & & & & & & & & & & & & & \\
\hline 2. Job Type & $.45^{* * *}$ & - & & & & & & & & & & & & & & \\
\hline 3. E Diss T1 & $-.11^{* * *}$ & $-.23^{* * *}$ & $(.93)$ & & & & & & & & & & & & & \\
\hline 4. MD T1 & $-.09^{* * *}$ & $-.12^{* * *}$ & $.24^{* * *}$ & (.79) & & & & & & & & & & & & \\
\hline 5. PSD T1 & $-.15^{* * *}$ & $-.17^{* * *}$ & $.32^{* * *}$ & $.68^{* * *}$ & $(.86)$ & & & & & & & & & & & \\
\hline 6. Control T1 & $.13^{* * *}$ & $.12^{* * *}$ & $-.25^{* * *}$ & $.05^{*}$ & .02 & $(.94)$ & & & & & & & & & & \\
\hline 7. Support T1 & $.07^{* * *}$ & $.08^{* * *}$ & $-.21^{* * *}$ & $-.04^{*}$ & -.04 & $.25^{* * *}$ & $(.92)$ & & & & & & & & & \\
\hline 8. CCSCS T1 & $-.07^{* * *}$ & $-.12^{* * *}$ & $.21^{* * *}$ & $.11^{* * *}$ & $.17^{* * *}$ & .01 & $-.06^{* *}$ & $(.82)$ & & & & & & & & \\
\hline 9. CCSAC T1 & $.07^{* *}$ & .03 & $.18^{* * *}$ & $.10^{* * *}$ & $.15^{* * *}$ & -.02 & $-.07^{* * *}$ & $.47^{* * *}$ & $(.77)$ & & & & & & & \\
\hline 10. CCSDE T1 & .03 & -.01 & $.21^{* * *}$ & .02 & .03 & $-.14^{* * *}$ & $-.15^{* * *}$ & $.34^{* * *}$ & $.55^{* * *}$ & $(.90)$ & & & & & & \\
\hline 11. CCSAV T1 & $.05^{*}$ & -.01 & $.19^{* * *}$ & -.00 & .02 & $-.16^{* * *}$ & $-.15^{* * *}$ & $.29^{* * *}$ & $.41^{* * *}$ & $.76^{* * *}$ & (.89) & & & & & \\
\hline 12. CCSSR T1 & $.09^{* * *}$ & $-.07^{* *}$ & $.20^{* * *}$ & $.09^{* * *}$ & $.11^{* * *}$ & $-.07^{* * *}$ & $-.04^{*}$ & $.30^{* * *}$ & $.33^{* * *}$ & $.40^{* * *}$ & $.41^{* * *}$ & (.69) & & & & \\
\hline 13. Eng T1 & $.11^{* * *}$ & $.09^{* *}$ & $-.23^{* * *}$ & $.11^{* * *}$ & $.07^{* * *}$ & $.39^{* * *}$ & $.40^{* * *}$ & -.01 & .00 & $-.15^{* * *}$ & $-.18^{* * *}$ & $-.06^{* *}$ & $(.92)$ & & & \\
\hline 14. Strain T1 & -.01 & -.03 & $.29^{* * *}$ & $.11^{* * *}$ & $.11^{* * *}$ & $-.28^{* * *}$ & $-.31^{* * *}$ & $.08^{* * *}$ & $.12^{* * *}$ & $.22^{* * *}$ & $.27^{* * *}$ & $.14^{* * *}$ & $-.41^{* * *}$ & $(.91)$ & & \\
\hline 15. Eng T2 & $.07^{* * *}$ & $.06^{* *}$ & $-.19^{* * * *}$ & $.08^{* * *}$ & $.06^{* *}$ & $.30^{* * *}$ & $.30^{* * *}$ & -.02 & .02 & $-.13^{* * *}$ & $-.14^{* * *}$ & $-.04^{*}$ & $.67^{* * *}$ & $-.30^{* * *}$ & $(.93)$ & \\
\hline 16. Strain T2 & .01 & -.01 & $.23^{* * * *}$ & $.08^{* * *}$ & $.09^{* * *}$ & $-.18^{* * *}$ & $-.20^{* * *}$ & .02 & $.05^{*}$ & $.13^{* * *}$ & $.10^{* * *}$ & $.08^{* * *}$ & $-.24^{* * *}$ & $.51^{* * *}$ & $-.38^{* * *}$ & $(.91)$ \\
\hline$M$ & - & - & 2.87 & 3.97 & 3.68 & 3.60 & 2.68 & 3.27 & 3.56 & 3.07 & 2.76 & 3.21 & 3.99 & 1.00 & 3.99 & 1.00 \\
\hline$S D$ & - & - & 1.06 & 0.78 & 0.83 & 0.89 & 1.95 & 1.37 & 1.26 & 1.27 & 1.19 & 1.31 & 1.41 & 0.47 & 1.42 & 0.47 \\
\hline
\end{tabular}

Table 1 note. E Diss = Emotional Dissonance; MD = Monitoring Demands; PSD = Problem Solving Demands; CCSCS = Cybernetic Coping Scale Change the Situation; CCSAC = Cybernetic Coping Scale Accommodation; CCSDE = Cybernetic Coping Scale Devaluation; CCSAV = Cybernetic Coping Scale Avoidance; CCSSR = Cybernetic Coping Scale Symptom Reduction; Eng = Engagement; T1 = Time 1; T2 = Time 2;

${ }^{*} p<.05 ;{ }^{* *} p<.01 ; * * p<.001$; Cronbach's alpha coefficients are depicted in parentheses along the diagonal. 


\section{MODERATED MEDIATION OF STRESS}

Table 2. Significant bootstrapped effects for cognitive demands on Engagement and Strain.

\begin{tabular}{|c|c|c|c|c|}
\hline \multicolumn{5}{|c|}{ Problem-Solving Demands $¥$ Accommodation x Support $¥$ T2 Engagement } \\
\hline & $b$ & $S E b$ & $t$ & $p$ \\
\hline Problem-Solving Demands $\ddagger$ Accommodation & .226 & .033 & 6.841 & $<.001$ \\
\hline Accommodation $\ddagger$ Engagement & .059 & .023 & 2.535 & .011 \\
\hline Accommodation x Support $\ddagger$ Engagement & -.050 & .019 & -2.532 & .011 \\
\hline Problem-Solving Demands ₹ Engagement & .039 & .029 & 1.384 & .166 \\
\hline \multicolumn{5}{|c|}{ Significant indirect effects (bolded) at $1 \mathrm{SD}+/$ - the Mean of the moderator } \\
\hline Supervisor Support & $b$ & $S E b$ & CI LL & CI UL \\
\hline Low & .024 & .008 & .009 & .042 \\
\hline Average & .013 & .006 & .003 & .026 \\
\hline High & .003 & .006 & -.009 & .015 \\
\hline \multicolumn{5}{|c|}{ Monitoring Demands $¥$ Accommodation x Support $\ddagger$ T2 Engagement } \\
\hline & $b$ & $S E b$ & $t$ & $p$ \\
\hline Monitoring Demands $\ddagger$ Accommodation & .163 & .036 & 4.533 & $<.001$ \\
\hline Accommodation $\ddagger$ Engagement & .059 & .023 & 2.547 & .011 \\
\hline Accommodation x Support $\ddagger$ Engagement & -.050 & .020 & -2.546 & .011 \\
\hline Monitoring Demands $\ddagger$ Engagement & .023 & .032 & 0.738 & .461 \\
\hline \multicolumn{5}{|c|}{ Significant indirect effects (bolded) at $1 \mathrm{SD}+/$ - the Mean of the moderator } \\
\hline Supervisor Support & $b$ & $S E b$ & CI LL & CI UL \\
\hline Low & .017 & .007 & .007 & .034 \\
\hline Average & .010 & .005 & .002 & .020 \\
\hline High & .002 & .004 & -.006 & .011 \\
\hline \multicolumn{5}{|c|}{ Monitoring Demands x Support $\ddagger$ Avoidance Coping $\ddagger$ T2 Strain } \\
\hline & $b$ & $S E b$ & $t$ & $p$ \\
\hline Monitoring Demands $¥$ Avoidance & -.016 & .039 & -0.420 & .675 \\
\hline Monitoring Demands x Support $\ddagger$ Avoidance & .083 & .042 & 1.974 & .049 \\
\hline Avoidance $\ddagger$ Strain & -.046 & .013 & -3.428 & .001 \\
\hline Monitoring Demands $\ddagger$ Strain & .019 & .014 & 1.362 & .173 \\
\hline \multicolumn{5}{|c|}{ Significant indirect effects (bolded) at $1 \mathrm{SD}+/$ - the Mean of the moderator } \\
\hline Supervisor Support & $b$ & $S E b$ & CI LL & CI UL \\
\hline Low & .004 & .003 & .0001 & .012 \\
\hline Average & .001 & .002 & -.003 & .005 \\
\hline High & -.003 & .003 & -.010 & .002 \\
\hline
\end{tabular}

Note. CI LL $=95 \%$ bias corrected confidence interval lower limit; CI UL $=95 \%$ bias corrected confidence interval upper limit. 


\section{MODERATED MEDIATION OF STRESS}

Table 3. Significant bootstrapped effects for emotional demands on Engagement.

\section{Emotional Demands x Control $¥$ Accommodation $¥$ T2 Engagement}

$\begin{array}{lcccc} & b & S E b & t & p \\ \text { Dissonance } ¥ \text { Accommodation } & .242 & .027 & 9.053 & <.001 \\ \text { Dissonance x Control } ¥ \text { Accommodation } & .065 & .028 & 2.287 & .022 \\ \text { Accommodation } \ddagger \text { Engagement } & .066 & .024 & 2.776 & .006 \\ \text { Dissonance } \ddagger \text { Engagement } & -.056 & .024 & -2.364 & .018\end{array}$

Significant indirect effects (bolded) at $1 \mathrm{SD}+/$ - the Mean of the moderator

Control

$b \quad$ SE $b \quad$ CI LL $\quad$ CI UL

Low

$\begin{array}{llll}.012 & .005 & .004 & .025\end{array}$

Average

$.016 \quad .006$

$.005 \quad .029$

High

.020

.008

.006

.036

Emotional Demands $¥$ Accommodation $x$ Support $¥$ T2 Engagement

$b \quad S E b \quad t \quad p$

Dissonance $\ddagger$ Accommodation

.236

.026

9.070

$<.001$

Accommodation $\ddagger$ Engagement

$.061 \quad .024$

2.610

.009

Accommodation x Support $\ddagger$ Engagement

$-.065 \quad .023$

$-2.847$

.005

Dissonance $\ddagger$ Engagement

$-.054$

.024

$-2.250$

.025

Significant indirect effects (bolded) at $1 \mathrm{SD}+/$ - the Mean of the moderator

Supervisor Support

$b \quad$ SE $b \quad$ CI LL $\quad$ CI UL

Low

$.029 \quad .009$

$.013 \quad .048$

Average

$.015 \quad .006$

.004

.027

High

$-.000 \quad .007$

.013

Note. CI LL $=95 \%$ bias corrected confidence interval lower limit; CI UL $=95 \%$ bias corrected confidence interval upper limit. 
Figure 1.

Simultaneous test of multiple third variables

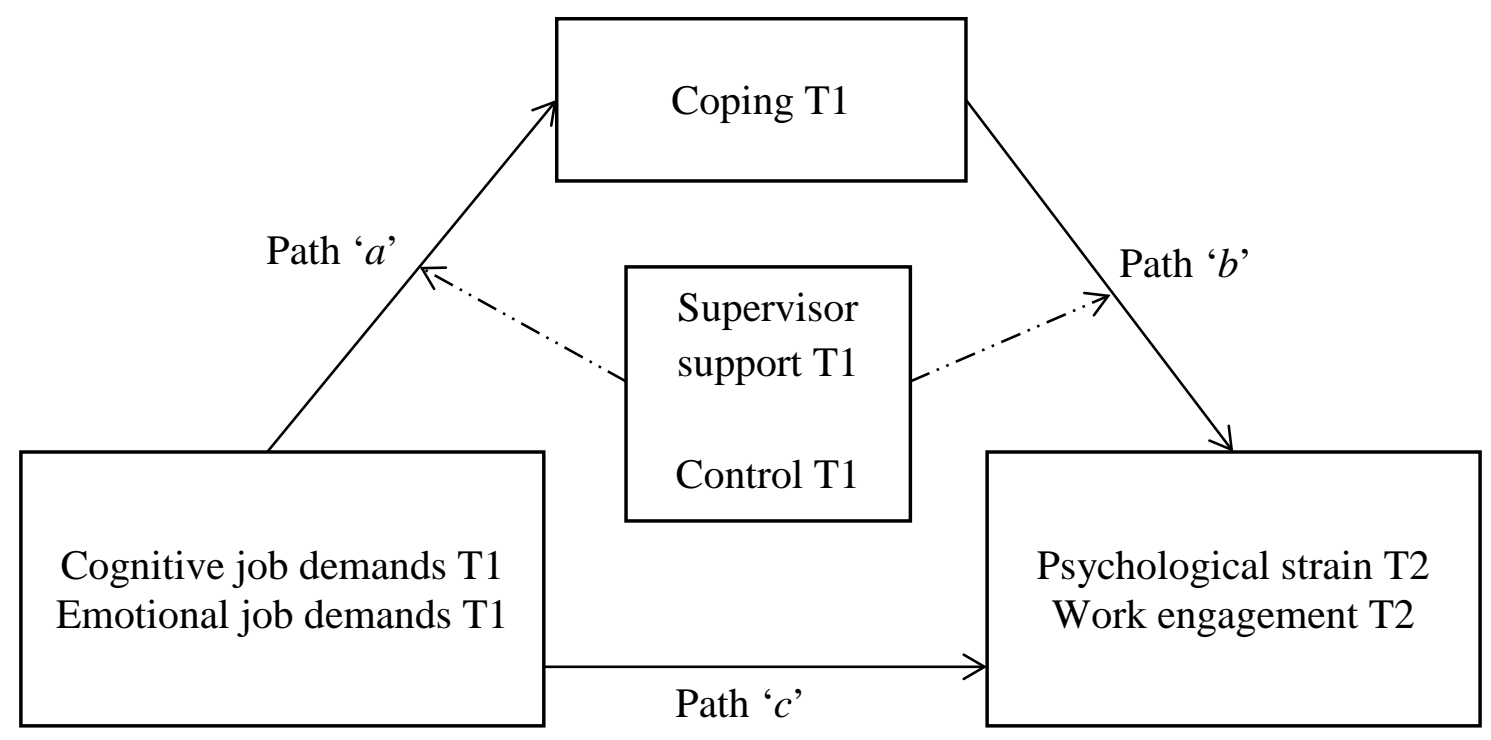

Note. Dashed lines indicate moderated pathways. T1 = Time 1, T2 = Time 2. 